\title{
Inherited Forms of Bladder Cancer: A review of Lynch Syndrome and Other Inherited Conditions
}

Aaron Phelan, $\mathrm{MD}^{1}$, Antonio Lopez-Beltran, $\mathrm{MD}^{2}$, Rodolfo Montironi, $\mathrm{MD}^{3}$, Shaobo Zhang, $\mathrm{MD}^{1}$, Maria R. Raspollini, MD ${ }^{4}$, Hristos Z. Kaimakliotis, MD ${ }^{5}$, Michael O. Koch, MD ${ }^{5}$, Liang Cheng, $\mathrm{MD}^{1,5}$

From Departments of Pathology ${ }^{1}$ and Pathology ${ }^{5}$, Indiana University School of Medicine, Indianapolis, USA; ${ }^{2}$ Unit of Anatomical Pathology, Faculty of Medicine, Cordoba, Spain and Champalimaud Clinical Center, Lisbon, Portugal; ${ }^{3}$ Institute of Pathological Anatomy and Histopathology, School of Medicine, Polytechnic University of the Marche Region (Ancona), United Hospitals, Ancona, Italy; ${ }^{5}$ Histopathology and Molecular Diagnostics. University Hospital Careggi, Florence, Italy.

Running Head: Bladder Cancer: Familial Variants and Heritability

Key words: Bladder, Lynch Syndrome, Urothelial Carcinoma, Molecular Genetics, Microsatellite instability (MSI), Screening

Total number of text pages, 18; Number of tables, 3; Number of figures, 2

Conflict of interest: None

Address correspondence and reprint requests to Liang Cheng, M.D., Department of Pathology and Laboratory Medicine, Indiana University School of Medicine, 350 West $11^{\text {th }}$ Street, IUHPL Room 4010, Indianapolis, IN 46202, USA. Telephone: 317-491-6442; Fax: 317-491-6419; E-mail: liang_cheng@yahoo.com

This is the author's manuscript of the article published in final edited form as:

Phelan, A., Lopez-Beltran, A., Montironi, R., Zhang, S., Raspollini, M. R., Cheng, M., ... Cheng, L. (2018). Inherited forms of bladder cancer: a review of Lynch syndrome and other inherited conditions. Future Oncology, 14(3), 277-290. https://doi.org/10.2217/fon-2017-0346 


\begin{abstract}
Environmental factors that play a role in the pathogenesis of bladder cancer have been characterized for many years. Current research into the pathophysiology of bladder cancers has begun to focus more on genetic alterations that are important in tumorigenesis. Low penetrance polymorphisms, such as $\mathrm{N}$-acetyl transferase 2, glutathione $\mathrm{S}$-transferase, and others have also shown to increase the risk of bladder cancer by altering the processing of environmental toxins. Additionally, Lynch syndrome is a well-known inheritable disease that increases the risk for a variety of cancers, including urothelial carcinomas. The development of bladder cancer is still not as well understood in Lynch syndrome as other classical Lynch syndrome associated cancers, such as colorectal and endometrial cancer. Research is continuously exploring potential heritable forms of bladder cancer. Screening of patients with known Lynch syndrome is also important to evaluate for development of new primary tumors. The focus of this article is to review the current available literature on familial bladder cancer variants, as well as to provide a review of Lynch syndrome and its association with urothelial tumors.
\end{abstract}




\section{Introduction}

In 2017, it is estimated that bladder cancer will compose $5 \%$ of all new cancer diagnoses at around 79,030 new cases[1]. Additionally, an anticipated 16,870 deaths (3\% of all projected cancer deaths) will be due to bladder cancer[1]. A number of factors have been identified that contribute to the development of bladder cancer. Environmental factors, such as cigarette smoking and exposure to aromatic amines have been identified as the major contributors to increased bladder cancer risk [2-4]. However, the genetic and inheritable components of bladder cancer remain more of a mystery. Identification of Mendelian inheritance patterns in bladder cancer has been difficult due to a limited number of familial cases to explore [5]. New case reports and case studies have slowly become available, as well as follow up on families with multiple effected members. Large case studies are also limited with few new studies available. The most information regarding the heritability of bladder cancers seems to arise from the new research into Lynch syndrome and low penetrance polymorphisms [6-8].

The association of Lynch syndrome with urothelial cancers is relatively new. Urothelial cancers were only recently included in the criteria that assist in the diagnosis of Lynch syndrome[8]. The malignancies classically associated with Lynch syndrome are colorectal cancer and, to a degree, endometrial cancer[9-14]. These tumors have seen much more extensive study in their relation to Lynch syndrome than urothelial and other cancers. Moreover, while the association between Lynch syndrome and upper tract urothelial cancers is apparent, the direct relationship between Lynch syndrome and bladder cancers is less well understood. Increases in bladder cancer in patients with Lynch syndrome may be the result of downstream seeding from primary upper tract cancers, and may not represent primary bladder cancers[8]. More research is necessary in this area to truly delineate the relationship. 
In addition to Lynch syndrome, research is also active regarding low penetrance polymorphisms and their relation to bladder cancer. The most prolific polymorphisms include Nacetyl transferase and glutathione S-transferase. The presence of these polymorphisms only slightly increases the individual risk of bladder cancer, but they are prevalent in certain populations. The role these polymorphisms play in familial clustering of bladder cancers is still poorly understood. However, multiple polymorphisms coupled with consistent environmental exposure may explain families with multiple generations affected by bladder cancer[7].

\section{Case based evidence for inherited variants of bladder cancer}

The first case study to mention a familial linked bladder cancer was published in the late 1950's. In this paper, Thelen and Schaebule presented monozygotic twins with transitional cell papillomas of the bladder[15]. Since that time, several additional case studies have presented families with multiple members affected by bladder cancers. A paper published in 1967 by Fraumeni and Thomas reported a father and three of his sons with bladder transitional cell carcinoma[16]. Blattner et al. published follow up for this family in 1983 with additional follow up by Mueller et al. in 2008[7, 17]. At that time, the niece of the proband had also been diagnosed with bladder cancer. All affected family members reported an extensive smoking history, but had no other identifiable environmental risk factors. Studies for the more common variable penetrance polymorphisms were also performed, but all affected family members were negative for the genes associated with higher bladder cancer risk.

Mcullough et al. also reported a family with six affected family members in only two generations. This family also had numerous other cancers[18]. In their paper from 2008, Mueller et al. also summarized 16 case studies involving 32 families with transitional cell 
carcinoma. Important factors to note in these cases are exposures to known environmental risk factors, mainly smoking and occupation exposure to aromatic amines. For 40 of the 86 affected individuals, smoking history was unavailable. In the remaining 46 patients, 33 had a positive smoking history. In this conglomerate of cases, smoking history was reported in at least one family member in all of the cases[7]. A more concise version of the table presented in that article is shown in Table 1[7, 16-28], with the addition of some more recent case studies.

Studies of more recent cases on familial clustering of bladder cancers include Ilic et al., where they describe a mother and son with bladder transitional cell carcinoma[27]. In addition, Brown et al. introduced two families with three cases of bladder transitional cell carcinoma each[28].

Deciphering the underlying predisposing factors in these families remains a challenge. Some patients had clear risk factors with smoking histories or occupational exposure to carcinogens. Others have no discernable risk factors, even when tested for cancer-predisposing polymorphisms. The paucity of available cases in this regard limits the information that can be ascertained from these case studies. Ultimately, more cases with are required to reach a more definitive conclusion.

\section{Population based evidence for inherited variants of bladder cancer}

Kramer et al. conducted a cross-sectional study in 1991 on 319 men with bladder cancer and another 319 neighborhood controls. In this study, an investigation was made into the relatives of the selected participants. The study looked at 1619 relatives of the men with bladder cancer and identified 14 family members with bladder cancer. Only seven effected family members were identified out of the 1773 members of the control group[29]. Kiemeney et al. 
reviewed the families of 190 bladder cancer patients in Iceland and found family members with urinary tract transitional cell carcinoma in 41 of the families. Of interest in this study is that $2^{\text {nd }}$

and $3^{\text {rd }}$ degree relatives were more commonly affected[30]. A large case-control study in the Netherlands looked at 8014 family members of patients with transitional cell carcinoma and 5673 control relatives. One hundred and one relatives with urinary tract cancers were found in the family members of patients with urinary tract transitional cell carcinoma, whereas only 38 family members were affected among controls[31]. A study from Spain of 1158 cases reported increased risk for developing bladder cancer in those with a positive family history. This was stronger among slow acetylators, but not to a degree that was statistically significant[32]. Goldgar et al. also looked at Utah databases to prove increased risk of cancer in family members of cancer patients. This risk was much greater when younger probands were viewed[33]. A twin study from Denmark, Sweden and Finland from Lichtenstein et al reported three to four fold higher relative risk of bladder cancer among monozygotic twins than among dizygotic twins[34]. Another twin study from 2016 studied the increased cancer risk for monozygotic and dizygotic twins in Nordic countries. This study showed a $2.2 \%$ cumulative increase in the risk of bladder and other urinary organs for patients who had a mono or dizygotic twin with urinary tract cancer[5]. Dong and Hemminki used the Swedish Family-Cancer Database for more than 5 million offspring. The risk was increased by 1.5 with one affected parent and 3.3 also with an effected sibling[35].

\section{Bladder cancer susceptibility genes}

Some of the most well known risk factors for bladder cancer are environmental toxins. Cigarette smoke and occupational exposure to aromatic amines have been well studied and their 
contribution is clear[2]. Less well understood, however, is how genetic differences between individuals and their ability to process these toxins effect the development of bladder cancer. Environmental toxins are processed by a number of different enzymes. Many polymorphisms have been identified that may increase the risk for developing bladder cancer[7].

$\mathrm{N}$-acetyl transferase 2 is one of the most prominent polymorphisms in the literature. This polymorphism is extremely prevalent, found in approximately $50 \%$ of Caucasians. The odds ratio of the development of bladder cancer in patients with this polymorphism is 1.4 (95\% CI 1.2-1.6)[7]. The protein product of this gene is responsible for detoxifying amines. A patient with the slow acetylator phenotype would therefore have a greater risk from exposure to environmental amines, either from cigarettes or occupational exposures. This longer exposure time increases the risk of bladder cancer. The fast acetylators would more quickly clear the toxins and would not be at as great of risk. Although some authors show evidence supporting this association, there is still contention as to whether there is sufficient statistical power to prove this relationship[36].

Another genetic polymorphism of interest is glutathione S-transferase. This family of enzymes, belonging to the mammalian glutathione transferase family, is responsible for catalyzing conjugation of electrophilic substrates with glutathione. This conjugation results in detoxification of certain chemicals. The glutathione S-transferase M1 gene in particular detoxifies polycyclic aromatic hydrocarbons, many of which have been identified as carcinogenic. Glutathione S-transferase M1 is important in cancer prevention, thus a deficiency in this gene or protein product results in susceptibility to malignancy. Lack of this gene and product can be found in those patients who have inherited two copies of the null gene. Those 
with the null phenotype for this gene find themselves at greater risk for developing bladder cancer[7, 37].

Some studies have estimated that $31 \%$ of bladder cancer in Caucasians may be due to deficiency of glutathione $\mathrm{S}$-transferase or $\mathrm{N}$-acetyl transferase 2. Additionally, many other gene variations have been studied and proposed as increasing the risk of familial bladder cancer[37]. These genes require more study, but give us more insight into the development of bladder cancer.

\section{Lynch Syndrome}

\subsection{Epidemiology}

Lynch syndrome, also known as hereditary nonpolyposis colorectal cancer is the most common cause of hereditary colorectal and endometrial cancers, accounting for approximately 1$3 \%$ of all colorectal cancers and $2-5 \%$ of all endometrial cancers[8]. Lynch syndrome is classically associated with increased risk of colorectal cancer, but also increases the risk of several other cancers (Table 2)[8, 38, 39]. In women, endometrial cancer may actually be the sentinel malignancy[11]. A subset of Lynch syndrome, Muir-Torre syndrome, can also result in skin and sebaceous gland malignancies[40]. Lynch syndrome patients are additionally at increased risk for ovarian, urinary tract, stomach, small bowel, hepatobiliary, and central nervous system neoplasms[8]. The association of Lynch syndrome with these neoplasms is still growing due to limitations of early studies of Lynch syndrome, including small sample size, lack of disease confirmation, and limited or no availability of genetic testing. There is also equivocal evidence that malignancies of the prostate, testis, kidney, and adrenal gland may be slightly increased in Lynch syndrome patients. The susceptibility in Lynch syndrome to these particular 
neoplasms is not as frequently reported and they may develop through pathways other than $\operatorname{MSI}[8]$.

The risk of urothelial tract cancer in Lynch syndrome has been reported to increase by up to $28 \%[8,41]$. Research shows these urothelial tract cancers to include renal pelvis and ureter tumors (Figure 1). Bladder cancers noted in cases of Lynch syndrome could be due to implantation of tumor cells from upstream into the bladder mucosa. The true risk may be even higher, with some urothelial cancers suspected to be misclassified as sporadic[8].

Research has shown that sporadic colorectal cancers have different characteristics than colorectal cancers associated with Lynch syndrome[8]. Lynch syndrome associated cancers present at a younger mean age, which are usually right sided, and more likely multifocal. Additionally, colon polyps in Lynch syndrome patients develop at a younger age, are smaller, and are more likely to be villous polyps. Differences between sporadic and Lynch syndrome associated urothelial cancers are also seen with Lynch syndrome patients more likely to develop urothelial cancers at a younger age (an average of 8 years younger according to one study), though one study showed no association with early bladder cancers and MSI. Additionally, there appears to be a slight female predominance and some studies suggest higher incidence of bilateral involvement of the upper urothelial tract[8]. One study suggested an association between inverted growth pattern and MSI and Lynch syndrome[42].

Prognosis and response to treatment also varies in sporadic versus Lynch syndrome associated colorectal cancers, and it has been postulated that the same may be true for urothelial cancers. Patients with Lynch syndrome associated colorectal cancers appear to have superior overall survival[8]. More research is still required to evaluate the differences between sporadic and Lynch syndrome associated urothelial cancers. 


\subsection{Genetics}

Lynch syndrome is an autosomal dominant genetic disease caused by mutations in mismatch repair (MMR) genes. Four mismatch repair genes can be mutated in Lynch syndrome, and a mutation in one of these genes predisposes to several different malignancies. The four MMR genes are MLH1, MSH2 (and its modifier EPCAM), MSH6, and PMS2. Mutations in these genes lead to accumulation of DNA errors in microsatellite regions of the genome. This phenomenon is also known as microsatellite instability (MSI). Microsatellites are short, noncoding, and repeating sequences of DNA. Instability in these regions as the result of shortening or lengthening of these repeating sequences can lead to malignant transformation of effected cells. The MMR deficiencies in Lynch syndrome lead to lengthening of these sequences, a.k.a., MSI-high tumors. The importance of MSI low tumors is not as well understood. Some sporadic tumors may also possess MSI high sequences, and this should also be taken into consideration when assessing for Lynch syndrome[8, 14].

Additionally, a mutation in the MSH2 gene seems to confer a higher risk for urothelial cancer than mutations in the other MMR genes. The increase in urothelial cancers is predominantly within the renal pelvis and ureters. Some studies have shown an increased risk for bladder cancer as well, but this increased risk may be due to seeding of the bladder from primary tumors that are upstream[8].

\subsection{Diagnosis}

When thinking of Lynch syndrome, clinicians classically associate this disease with GI malignances, thus a disease specific to gastroenterologists. However, urologists also need to be aware of Lynch syndrome when patients present with primary bladder cancers. Urologists play 
important roles in identifying, screening, and treating patients with Lynch syndrome. Clinical criteria, tumor tissue testing, and genetic germline testing are all available to assist in the diagnosis of Lynch syndrome. Upper urinary tract cancers are considered a core malignancy of Lynch syndrome and are included in both the revised Bethesda Guidelines and the Amsterdam II criterion [8].

The initial Bethesda Guidelines were developed in 1996, when an international workshop was hosted by the National Cancer Institute to further the clinical and histological manifestations of Lynch syndrome and MSI testing. These guidelines were revised at a similar workshop in 2002. The revised Bethesda Guidelines works to identify those patients in which Lynch syndrome testing is warranted in order to aid providers in appropriate patient care. The revised Bethesda Guidelines provide five scenarios in which Lynch syndrome testing should be pursued. The first scenario suggests testing in patients who present with colorectal cancer and are less than 50 years old. Patients with synchronous or metasynchronous Lynch syndrome associated tumors should be tested regardless of age. Those patients with colon cancer who have a high MSI histology (defined as tumor infiltrating lymphocytes, Crohn's like lymphocytic reaction, mucinous/signet ring differentiation, or medullary growth pattern) who are less than 60 years old should also be tested. A family history of colorectal cancer and another Lynch syndrome associated cancer diagnosed in at least one first-degree relative also indicates the need for testing. The final Bethesda Guideline recommends testing in the instance of two first or seconddegree relatives with colorectal cancer and a second Lynch syndrome associated tumor, regardless of their age [43].

Initial identification of Lynch syndrome in patients who present with urothelial cancers is similar to algorithms used with colorectal cancers[8]. Screening for patients with colon cancer 
usually takes the form of MSI testing in patients with colorectal cancer who are younger than 50 years old. This form of testing is generally cost effective while also detecting most of the patients with Lynch syndrome. Prediction models can also be helpful[13, 14, 43].

Testing for MSI in urothelial tumors should be focused on those patients for whom there is high clinical suspicion (Figure 2). The clinical history is paramount in identifying those patients who would benefit most from testing. An extensive family pedigree is a major aid and should be collected on all patients. The Bethesda Guidelines and the Amsterdam II criterion are a useful tool for clinicians. The Amsterdam II criteria, however, are somewhat strict and may fail to identify some patients with Lynch syndrome. The sensitivity of the criteria have been reported to be approximately $72 \%$, and studies using more broad criteria for testing have been able to identify additional Lynch syndrome patients that were missed on screening with the Amsterdam II criteria. Some international guidelines use upper tract urothelial cancer and age less than 60 as a trigger for genetic testing[ 8,43$]$.

Patients who present at a young age ( $<60$ years), with a family history of urothelial, colorectal, or endometrial cancers, or those patients who have a personal history of colorectal or endometrial cancer should have malignant tissue tested for MSI. Initial testing should be performed with immunohistochemistry or PCR testing. The national cancer institute has suggested a 5-marker panel including five different alleles for MSI testing. A shift in 30\% or more of these alleles is necessary for the tissue to be designated as MSI high. PCR testing may be necessary as $10 \%$ of MMR mutated tumors may not have loss of proteins on immunohistochemical testing[8, 43].

Immunohistochemical testing of tissue uses protein specific antibodies to highlight the loss of the MMR proteins by staining the products of the MLH1, MSH2, MSH6, and PMS2. For 
MSI high tumors or tumors with protein loss, germline genetic testing should be considered. In cases where the immunohistochemistry has revealed loss of a specific protein, the focus of the testing can be targeted at the specific gene. If tumor tissue cannot be adequately tested in a family where suspicion for Lynch syndrome is high, comprehensive germline genetic testing of the MMR genes can also be performed. Existing prediction models can assist in these cases where tumor testing is unavailable. Loss of MLH1 and PMS2 on IHC can also be due to BRAF V600E mutation and MLH1 hyper methylation, and these should be ruled out in colorectal tumor samples before pursuing genetic testing. It is important to keep in mind with regard to MMR testing that the testing has been validated for colorectal and endometrial tumor specimen. Therefore, negative studies in other tissue types may not necessarily exclude the possibility of Lynch syndrome[8, 14, 43].

\subsection{Screening for urothelial cancers in patients with diagnosed Lynch syndrome}

Patients with Lynch syndrome require a number of distinct considerations in regard to screening for Lynch syndrome associated cancers. Colonoscopies in these patients should be performed earlier and more frequently. The appropriate frequency and age of first colonoscopy can vary depending on particular gene effected within the family, as well as the age of first colorectal cancer diagnosis in the family[14]. Additionally, female Lynch syndrome patients should be advised to consider early hysterectomy to prevent endometrial cancers[11].

Patients with diagnosed Lynch syndrome require special consideration for early identification of urothelial tract cancers. There is still no widely agreed upon method for screening these patients. Urinalysis and urine cytology remain the default screening method for patients with Lynch syndrome. These methods are fairly cheap and noninvasive which make 
them an easy to perform screening test. Urine cytology, however, has a low sensitivity of approximately $29 \%$, despite its high specificity for high grade lesions. This means that many patients with low-grade urinary tract cancers can easily be overlooked with this testing. Therefore, urine cytology should not be used alone for screening Lynch syndrome patients for urothelial cancers. Other suggested methods have included renal ultrasound, urine dipstick, and NMP-22 testing. Patients with a previously diagnosed urothelial tract cancer or the MSH-2 mutation are considered to be at higher risk of tumor formation and vigilance in these patients is prudent $[8]$.

Hematuria identified on urinalysis can be a concerning feature and should be investigated further. Gross hematuria requires the default urological evaluation, including cystoscopy and biopsy. Microhematuria as a tool has low sensitivity for the evaluation of recurrent upper tract cancers, with a sensitivity of approximately $37.5 \%$. Microhematuria is also relatively common in the general population, with no history of urothelial cancers[8]. One study revealed $41 \%$ of the general population to have a urinalysis with microhematuria[44]. Microhematuria should trigger further evaluation with greater than 3 red blood cells per high power field.

Routine imaging studies in patients with Lynch syndrome are common, but also pose risk with increased radiation exposure. Patients with a previously diagnosed malignancy can expect yearly CT imaging. Patients at higher risk, those with previous upper urothelial tract cancers or PMS2 mutations, may benefit from routine CT urograms[8].

More definitive methods for identifying early urothelial tract tumors are not without their risks. Cystoscopy is minimally invasive, visualization of the ureters and renal pelvis requires more risk to the patient. This may include radiation exposure and exposure to anaesthetic[45]. 
The association of Lynch syndrome with urothelial cancers is not as old as the association with colorectal and other cancers. It was not until the Amsterdam Criteria II revision in 1999 (Table 3)[34] that non-colonic Lynch syndrome cancers began to be truly appreciated.

Therefore, more research is required to hone our knowledge regarding urothelial cancers and Lynch syndrome [8].

Patients with Lynch syndrome have increased risk of bladder cancer. The recommendations of Mork et. al. in their 2015 article on Lynch syndrome and urothelial cancers are frequent screens for hematuria on urinalysis, with a threshold of $3 \mathrm{RBC} / \mathrm{HPF}$. Additionally, for patients with previous Lynch syndrome malignancies, CT urogram or MR urogram can be performed to assess for upper tract malignancies[8].

\section{Conclusions}

The medical literature to this point does not provide irrefutable evidence for a true Mendelian pattern bladder cancer. Since the first case report by Thelen and Schaebule, many more cases have been reported which portray many families with multiple members affected by bladder cancer. Additional risk factors are present within many of these families, making it more difficult to elucidate the true role of inheritance. With these environmental exposures in common to explain the familial clustering, a true Mendelian cause becomes less likely. Population based studies using large patient databases have also given us some information. All of these studies have revealed that relatives of patients with bladder cancer are more likely to develop bladder cancer themselves when compared to the general population. Part of this increased risk could be attributed to shared environmental factors, as in some of the individual case studies. Close relatives are likely to share important history characteristics, such as 
smoking and occupational exposures to aromatic amines. In addition, the case literature is limited in that most of these cases follow only a couple of generations. Few multigenerational cases have been reported. Not all of these population based studies may have the important historical data available, but even so, it seems unlikely that all of the familial clustering can be attributed to environmental risk factors. This is where the genetic polymorphisms may play a role. Many polymorphisms have come to light that seem to increase the risk of bladder cancer. The NAT2 and glutathione transferase genes seem to be some of the more well studied genes, but many more have been characterized as increasing the risk of bladder cancer. Even more so, other cancer predisposition syndromes such as Lynch syndrome have shown that they can lead to increased incidence of bladder cancer. These add an additional level of difficulty when trying to evaluate families for potential Mendelian patterns of inheritance. At this point, more study is required to more clearly elucidate the myriad factors involved in the development of bladder cancer.

Lynch syndrome is one important factor to consider in inherited urothelial tumors. Though these types of tumors are less well studied in Lynch syndrome, the current research clearly shows the increased risk of urothelial tumors in this syndrome. Screening of patients with known Lynch syndrome is also important to evaluate for development of new primary tumors.

\section{Future Perspective}

The coming years will undoubtedly bring us a greater understanding of the genetics of bladder cancer. Study into these genetic alterations is becoming a topic of increasing interest 
with many new polymorphisms being identified, as well as our understanding of urothelial cancers in Lynch syndrome being refined.

Much can be expected to surface about the association of Lynch syndrome and its role in urothelial cancers. Bladder, ureter, and renal pelvis cancers remained an underappreciated portion of the syndrome until the last couple of decades. This recognition has allowed an increasing number studies to shine light on these associations. In the future we will likely see further and more expansive studies to refine our understanding. The real association of Lynch syndrome and bladder cancer is still poorly understood, for example. We currently do not fully understand the actual risk of bladder cancer in Lynch syndrome. Increases in incidence may simply be due to downstream seeding from upper tract cancers. Further studies will no doubt illuminate this problem and provide us with more concrete answers.

Next generation sequencing is only just starting to blossom. Sequencing at this point is still expensive and the sequencing of multiple patients for study may not be practical in all cases. As with most advances, the cost of next generation sequencing will likely decline rapidly over the coming years. As this process is made more efficient and cost effective we will see increased application in large scale studies in many areas, including bladder cancer and urothelial cancer research. Large scale application of this process will lead to the discovery of many additional genes in carcinogenesis in addition to improving our understanding in epidemiology for currently poorly understood alterations, such as many of the single nucleotide polymorphisms, which have limited evidence.

Additionally, screening for patients with Lynch syndrome may see changes in the coming years. Currently proposed screening methods involve measuring hematuria and the use of urine cytology with some providers using more costly and invasive measures such as cystoscopy or CT 
and MRI. Further study may provide more information on what level of follow-up each patient needs. We can already see that some mismatch repair mutations confer a greater risk for urothelial cancer. Additional large patient series as well as advancement of molecular testing may provide triage for Lynch syndrome patients in regards to the frequency and type of screening best suited for each patient. 


\section{Executive Summary}

\section{Case Based Evidence for Inherited Variants of Bladder Cancer}

- Familial clustering of bladder cancer that cannot be attributed to known genetic predispositions has been observed in multiple case studies.

- Many of the effected family members in these case studies do share some environmental predispositions such as smoking and occupational exposures.

- The evidence is suggestive of additional genetic predispositions to bladder cancer, but no definitive conclusions can be made and further research is required.

\section{Population based evidence for inherited variants of bladder cancer}

- Patients with bladder cancer are more likely than the general population to have relatives who also have a history of bladder cancer.

\section{Bladder cancer susceptibility genes}

- $\mathrm{N}$-acetyl transferase 2 polymorphism has been shown in some studies to increase the risk of bladder cancer.

- $\mathrm{N}$-acetyl transferase 2 is found in approximately $50 \%$ of the Caucasian population.

- The slow acetylator phenotype for $\mathrm{N}$-acetyl transferase 2 results in longer exposure times to environmental factors proven to cause bladder cancer.

- Glutathione S-transferase M1 is responsible for detoxifying polycyclic aromatic hydrocarbons.

- Inheritance of two null copies of the Glutathione S-transferase M1 gene result in a higher risk of bladder cancer. 


\section{Lynch syndrome}

- The risk of urothelial tract cancer in Lynch syndrome has been reported to increase by up to $28 \%$.

- Urothelial cancers in Lynch syndrome have been shown by some studies to be diagnosed at younger ages and have a slight female predominance.

- Lynch syndrome is caused by mutations in one of the mismatch repair genes: MLH1, MSH2, MSH6, and PMS2

- Mutations in MSH2 have been shown to confer higher incidence of urothelial cancer in Lynch syndrome.

- History coupled with the Amsterdam II or revised Bethesda criteria can be used to triage IHC, PCR, and germline genetic testing in patients with urothelial cancers.

- Hematuria with a threshold of $3 \mathrm{rbc} / \mathrm{hpf}$ can be used for urothelial cancer screening in patients with Lynch syndrome. 


\section{References:}

1. Siegel RL, Miller KD, Jemal A. Cancer statistics, 2017. CA Cancer J Clin 67(1), 7-30 (2017).

2. Antoni S, Ferlay J, Soerjomataram I, Znaor A, Jemal A, Bray F. Bladder cancer incidence and mortality: a global overview and recent trends. Eur Urol 71(1), 96-108 (2017).

3. Cheng L, Lopez-Beltran A, Bostwick Dg. Bladder Pathology. Wiley-Blackwell, Hoboken, NJ. (2012).

4. Alexander RE, Wang L, Lopez-Beltran A et al. Human papillomavirus (HPV)-induced neoplasia in the urinary bladder: a missing link? Histol Histopathol 31(6), 595-600 (2016).

5. Mucci LA, Hjelmborg JB, Harris JR et al. Familial Risk and Heritability of Cancer Among Twins in Nordic Countries. JAMA 315(1), 68-76 (2016).

6. Kiemeney LA. Hereditary bladder cancer. Scand J Urol Nephrol Suppl doi:10.1080/03008880802283755(218), 110-115 (2008).

7. Mueller CM, Caporaso N, Greene MH. Familial and genetic risk of transitional cell carcinoma of the urinary tract. Urol Oncol 26(5), 451-464 (2008).

8. Mork M, Hubosky SG, Roupret M et al. Lynch syndrome: a primer for urologists and panel recommendations. J Urol 194(1), 21-29 (2015).

9. Cheng L, Zhang Dy, Eble Jn. Molecular Genetic Pathology. $\left(2^{\text {nd }}\right)$. Springer, New York, NY. (2013).

10. Cheng L, Eble Jn. Molecular Surgical Pathology. Springer, New York, NY. (2013).

11. Mills AM, Longacre TA. Lynch syndrome: female genital tract cancer diagnosis and screening. Surg Pathol Clin 9(2), 201-214 (2016). 
12. Lynch HT, Snyder CL, Shaw TG, Heinen CD, Hitchins MP. Milestones of Lynch syndrome: 1895-2015. Nat Rev Cancer 15(3), 181-194 (2015).

13. Lynch HT, Lynch PM, Lanspa SJ, Snyder CL, Lynch JF, Boland CR. Review of the Lynch syndrome: history, molecular genetics, screening, differential diagnosis, and medicolegal ramifications. Clin Genet 76(1), 1-18 (2009).

14. Sehgal R, Sheahan K, O'connell PR, Hanly AM, Martin ST, Winter DC. Lynch syndrome: an updated review. Genes (Basel) 5(3), 497-507 (2014).

15. Thelen A, Schaeuble J. Simultaneous occurrence of bladder papilloma in uniovular twins. Z Urol 50(4), 188-195 (1957).

16. Fraumeni JF, Jr, Thomas LB. Malignant bladder tumors in a man and his three sons. JAMA 201(7), 507-509 (1967).

17. Blattner $\mathrm{Wa}$, Green $\mathrm{Mh}$, Goedert Jj. Interdisciplinary studies in the evaluation of persons at high risk of cancer. New York: Academic Press (1983).

18. Mccullough DL, Lamma DL, Mclaughlin AP, 3rd, Gittes RF. Familial transitional cell carcinoma of the bladder. J Urol 113(5), 629-635 (1975).

19. Benton B, Henderson BE. Environmental exposure and bladder cancer in young males. $J$ Natl Cancer Inst 51(1), 269-270 (1973).

20. Leklem JE, Brown RR. Abnormal tryptophan metabolism in a family with a history of bladder cancer. J Natl Cancer Inst 56(6), 1101-1104 (1976).

21. Sharma SK, Bapna BC, Singh SM. Familial profile of transitional cell carcinoma. $B r J$ Urol 48(6), 442 (1976).

22. Purtilo DT, Mccarthy B, Yang JP, Friedell GH. Familial urinary bladder cancer. Semin Oncol 6(2), 254-256 (1979). 
23. Lynch HT, Kimberling WJ, Lynch JF, Brennan K. Familial bladder cancer in an oncology clinic. Cancer Genet Cytogenet 27(1), 161-165 (1987).

24. Mahboubi AO, Ahlvin RC, Mahboubi EO. Familial aggregation of urothelial carcinoma. J Urol 126(5), 691-692 (1981).

25. Egilsson V, Einarsson GV, Thorhallsson P, Ingvarsson S. Urinary system tumours in a family. Eur J Cancer 29(16), 2335-2336 (1993).

26. Kenet G, Mandel M, Mor Y et al. Genetic predisposition and cyclophosphamide treatment in a girl with bladder carcinoma? Med Pediatr Oncol 24(4), 269-270 (1995).

27. Ilic M, Stojadinovic M, Milosavljevic Z. Familial aggregation of bladder cancer. Vojnosanit Pregl 68(5), 447-451 (2011).

28. Brown R, Donnelly DE, Allen D, Loughrey MB, Morrison PJ. Familial urothelial cell carcinoma of the bladder with autosomal dominant inheritance and late onset phenotype. Springerplus 3281 (2014).

29. Kramer AA, Graham S, Burnett WS, Nasca P. Familial aggregation of bladder cancer stratified by smoking status. Epidemiology 2(2), 145-148 (1991).

30. Kiemeney LA, Moret NC, Witjes JA, Schoenberg MP, Tulinius H. Familial transitional cell carcinoma among the population of Iceland. J Urol 157(5), 1649-1651 (1997).

31. Aben KK, Witjes JA, Schoenberg MP, Hulsbergen-Van De Kaa C, Verbeek AL, Kiemeney LA. Familial aggregation of urothelial cell carcinoma. Int J Cancer 98(2), 274-278 (2002).

32. García-Closas M, Malats N, Silverman D et al. NAT2 slow acetylation, GSTM1 null genotype, and risk of bladder cancer: results from the Spanish Bladder Cancer Study and meta-analyses. Lancet 366(9486), 649-659 (2005). 
33. Goldgar DE, Easton DF, Cannon-Albright LA, Skolnick MH. Systematic populationbased assessment of cancer risk in first-degree relatives of cancer probands. $J$ Natl Cancer Inst 86(21), 1600-1608 (1994).

34. Lichtenstein P, Holm NV, Verkasalo PK et al. Environmental and heritable factors in the causation of cancer--analyses of cohorts of twins from Sweden, Denmark, and Finland. $N$ Engl J Med 343(2), 78-85 (2000).

35. Dong C, Hemminki K. Modification of cancer risks in offspring by sibling and parental cancers from 2,112,616 nuclear families. Int J Cancer 92(1), 144-150 (2001).

36. Pesch B, Gawrych K, Rabstein S et al. N-acetyltransferase 2 phenotype, occupation, and bladder cancer risk: results from the EPIC cohort. Cancer Epidemiol Biomarkers Prev 22(11), 2055-2065 (2013).

37. Jiang Z, Li C, Wang X. Glutathione S-transferase M1 polymorphism and bladder cancer risk: a meta-analysis involving 33 studies. Exp Biol Med (Maywood) 236(6), 723-728 (2011).

38. Aarnio M, Sankila R, Pukkala E et al. Cancer risk in mutation carriers of DNAmismatch-repair genes. Int J Cancer 81(2), 214-218 (1999).

39. Skeldon SC, Semotiuk K, Aronson M et al. Patients with Lynch syndrome mismatch repair gene mutations are at higher risk for not only upper tract urothelial cancer but also bladder cancer. Eur Urol 63(2), 379-385 (2013).

40. John AM, Schwartz RA. Muir-Torre syndrome (MTS): an update and approach to diagnosis and management. J Am Acad Dermatol 74(3), 558-566 (2016).

41. Crockett DG, Wagner DG, Holmang S, Johansson SL, Lynch HT. Upper urinary tract carcinoma in Lynch syndrome cases. J Urol 185(5), 1627-1630 (2011). 
42. Hartmann A, Dietmaier W, Hofstadter F, Burgart LJ, Cheville JC, Blaszyk H. Urothelial carcinoma of the upper urinary tract: inverted growth pattern is predictive of microsatellite instability. Hum Pathol 34(3), 222-227 (2003).

43. Umar A, Boland CR, Terdiman JP et al. Revised bethesda guidelines for hereditary nonpolyposis colorectal cancer (Lynch syndrome) and microsatellite instability. $J$ Natl Cancer Inst 96(4), 261-268 (2004).

44. Loo RK, Lieberman SF, Slezak JM et al. Stratifying risk of urinary tract malignant tumors in patients with asymptomatic microscopic hematuria. Mayo Clin Proc 88(2), 129-138 (2013).

45. Hiorns MP. Imaging of the urinary tract: the role of CT and MRI. Pediatr Nephrol 26(1), 59-68 (2011).

Acknowledgements: The authors would like to thank Natasha Gibson for excellent editorial assistance. 


\section{Figure Legends}

\section{Figure 1. Morphology of urothelial carcinoma in a Lynch syndrome patient}

The figure shows representative histologic images of a 78-year-old female Lynch syndrome patient with high-grade papillary urothelial cell carcinoma in a ureter. A. Low power view of a cross section of ureter filled with tumor. B. Low power view showing tumor papillary architecture. C. High power view showing high-grade full thickness atypia of the urothelium. D. High power view showing nuclear pleomorphism.

Figure 2. Algorithm for MSI testing in urothelial cancers. The identification of Lynch syndrome begins with clinical suspicion based upon family history, patient history, and pedigree as outlined in the Bethesda guidelines and the Amsterdam II criteria. MSI testing by IHC can be performed alone, or in conjunction with PCR methods (IHC alone may miss a subset of Lynch cases). Loss of protein expression on IHC, or detection of MSI-high alterations on PCR warrant further testing, including genetic counselor consultation and germline genetic testing. UUTC: upper urinary tract cancer. 
Table 1. Familial Bladder Cancer Case Studies

\begin{tabular}{|c|c|c|c|c|c|}
\hline Author & $\begin{array}{l}\text { Year of } \\
\text { Study }\end{array}$ & $\begin{array}{l}\text { Relation to } \\
\text { proband }\end{array}$ & Sex & Age & $\begin{array}{l}\text { Environmental } \\
\text { Risk Factors }\end{array}$ \\
\hline \multirow{5}{*}{$\begin{array}{l}\text { Fraumeni[16] } \\
\text { Blattner[17] } \\
\text { Mueller[7] }\end{array}$} & \multirow{5}{*}{$\begin{array}{l}1967 \\
1983 \\
2008\end{array}$} & Proband & Male & 58 & Smoking \\
\hline & & Sibling & Male & 59 & Smoking \\
\hline & & Sibling & Female & 70 & Smoking \\
\hline & & $\begin{array}{l}\text { Paternal } \\
\text { Cousin }\end{array}$ & Female & 66 & Smoking \\
\hline & & Father & Male & 54 & Smoking \\
\hline \multirow[t]{2}{*}{ Benton[19] } & \multirow[t]{2}{*}{1973} & Proband & Male & 19 & Machinist \\
\hline & & Father & Male & Unknown & Welder \\
\hline \multirow[t]{6}{*}{ Mcullough[18] } & \multirow[t]{6}{*}{1975} & Proband & Male & 36 & Smoking \\
\hline & & Sibling & Male & 35 & $\begin{array}{l}\text { Smoking } \\
\text { Printer }\end{array}$ \\
\hline & & Father & Male & 44 & $\begin{array}{l}\text { Smoking } \\
\text { Painter }\end{array}$ \\
\hline & & $\begin{array}{l}\text { Paternal } \\
\text { Uncle }\end{array}$ & Male & 65 & Mechanic \\
\hline & & $\begin{array}{l}\text { Paternal } \\
\text { cousin }\end{array}$ & Female & 48 & Lived on a farm \\
\hline & & $\begin{array}{l}\text { Paternal } \\
\text { Uncle }\end{array}$ & Male & 60 & $\begin{array}{l}\text { Smoking } \\
\text { Farmer }\end{array}$ \\
\hline \multirow[t]{2}{*}{ Leklem[20] } & \multirow[t]{2}{*}{1976} & Proband & Female & 65 & $\begin{array}{l}\text { Smoking } \\
\text { Art teacher }\end{array}$ \\
\hline & & Sibling & Male & 51 & $\begin{array}{l}\text { Smoking } \\
\text { Petroleum plant }\end{array}$ \\
\hline \multirow[t]{2}{*}{ Sharma[21] } & \multirow[t]{2}{*}{1976} & Proband & Male & 83 & Smoking \\
\hline & & Child & Male & 58 & None known \\
\hline \multirow[t]{9}{*}{ Purtilo[22] } & \multirow[t]{9}{*}{1979} & Proband & Male & 62 & $\begin{array}{l}\text { Smoking } \\
\text { Textile dye }\end{array}$ \\
\hline & & Sibling & Male & 55 & $\begin{array}{l}\text { Smoking } \\
\text { Machinist }\end{array}$ \\
\hline & & Proband & Male & 59 & $\begin{array}{l}\text { Smoking } \\
\text { Textile dye }\end{array}$ \\
\hline & & Sibling & Male & 56 & $\begin{array}{l}\text { Smoking } \\
\text { Leather }\end{array}$ \\
\hline & & Proband & Male & 91 & None known \\
\hline & & Sibling & Female & 89 & None known \\
\hline & & Proband & Male & 39 & $\begin{array}{l}\text { Smoking } \\
\text { Machinist }\end{array}$ \\
\hline & & Sibling & Male & 52 & None known \\
\hline & & Proband & Male & 33 & Smoking \\
\hline
\end{tabular}




\begin{tabular}{|c|c|c|c|c|c|}
\hline & & & \multirow{2}{*}{ Female } & \multirow[b]{2}{*}{19} & \multirow{2}{*}{$\begin{array}{l}\text { Bricklayer } \\
\text { Dye }\end{array}$} \\
\hline & & Child & & & \\
\hline & & Sibling & Male & 28 & $\begin{array}{l}\text { Smoking } \\
\text { Bricklayer }\end{array}$ \\
\hline & & Proband & Male & 73 & $\begin{array}{l}\text { Smoking } \\
\text { Electrician }\end{array}$ \\
\hline & & Child & Male & 62 & $\begin{array}{l}\text { Smoking } \\
\text { Electrician }\end{array}$ \\
\hline \multirow[t]{5}{*}{ Lynch[23] } & \multirow[t]{5}{*}{1979} & Proband & Male & 52 & Organic chemist \\
\hline & & Father & Male & 68 & Radiologist \\
\hline & & Proband & Male & 50 & $\begin{array}{l}\text { Smoking } \\
\text { Wiring }\end{array}$ \\
\hline & & Sibling & Male & 24 & Smoking \\
\hline & & Sibling & Male & 49 & Smoking \\
\hline \multirow[t]{3}{*}{ Mahboubi[24] } & \multirow[t]{3}{*}{1981} & Proband & Female & 66 & None known \\
\hline & & Sibling & Male & 64 & $\begin{array}{l}\text { Smoking } \\
\text { Farmer }\end{array}$ \\
\hline & & Child & Male & 50 & $\begin{array}{l}\text { Smoking } \\
\text { Farmer } \\
\text { Pilot } \\
\text { Construction }\end{array}$ \\
\hline \multirow[t]{2}{*}{ Egilsson[25] } & \multirow[t]{2}{*}{1993} & Proband & Female & 76 & Farm \\
\hline & & Child & Male & 81 & $\begin{array}{l}\text { Smoking } \\
\text { Farm }\end{array}$ \\
\hline \multirow[t]{2}{*}{ Kenet[26] } & \multirow[t]{2}{*}{1995} & Proband & Female & 14 & Cyclophosphamide \\
\hline & & Grandparent & Male & Unknown & None known \\
\hline \multirow[t]{3}{*}{ Ilíc[27] } & \multirow[t]{3}{*}{2011} & Proband & Male & 68 & $\begin{array}{l}\text { Smoking } \\
\text { Farmer }\end{array}$ \\
\hline & & Parent & Female & 82 & Farmer \\
\hline & & Spouse & Female & 63 & Farmer \\
\hline \multirow[t]{6}{*}{ Brown[28] } & \multirow[t]{6}{*}{2014} & Proband & Male & 76 & Smoking \\
\hline & & Sibling & Male & 73 & Smoking \\
\hline & & Sibling & Female & 60 & Smoking \\
\hline & & Proband & Male & 60 & None Known \\
\hline & & Child & Female & 76 & None Known \\
\hline & & Child & Male & 50 & None Known \\
\hline
\end{tabular}


Table 2. Cancer risks in Lynch syndrome by anatomic sites

\begin{tabular}{|l|l|}
\hline Anatomical site & Cancer risk (\%) \\
\hline Central nervous system & $1-3$ \\
\hline Hepatobiliary & $1.4-4$ \\
\hline Pancreas & $1-6$ \\
\hline Colon & $15-80$ \\
\hline Upper urinary tract & $1-28$ \\
\hline Bladder & $2-6$ \\
\hline Skin/sebaceous gland neoplasm & $1-9$ \\
\hline Stomach & $1-13$ \\
\hline Small bowel & $3-6$ \\
\hline Ovary & $1-24$ \\
\hline Endometrium & $15-60$ \\
\hline Kidney & 3.3 \\
\hline
\end{tabular}


Table 3. Amsterdam II Criteria

Amsterdam II Criteria

- Three with histologically verified colorectal cancer, endometrial cancer, small bowel cancer, ureter cancer, or cancer of the renal pelvis.

- Cancer involving two or more generations.

- One or more cancer diagnoses in a family before 50 years of age. 